\title{
MECANISMO DE SOLUÇÃO DE CONTROVÉRSIAS NA OMC E APLICAÇÃO DE PRINCÍPIOS GERAIS DE DIREITO'
}

Patrícia Amaral Milbradt

\section{INTRODUÇÃO}

O presente trabalho tem como objetivo demonstrar de que forma ocorre a atuação do Órgão de Solução de Controvérsias (OSC) da Organização Mundial do Comércio (OMC) na resolução dos conflitos decorrentes das relações comerciais entre os seus Estados Membros, bem como analisar quais são os princípios gerais de direito, contidos no Entendimento sobre Solução de Controvérsias, mais empregados em suas decisões e de que forma eles são compreendidos e utilizados pelos Membros envolvidos na disputa.

A análise dos princípios aplicados pelo Mecanismo de Solução de Controvérsias terá como foco a interpretação jurídica dos dispositivos presentes nos diversos Acordos que compõem a base do direito material do OMC.

O trabalho será estruturado da seguinte forma: primeiramente, conterá um panorama geral de como e por que surgiu a OMC, contendo as maiores contribuições trazidas por ela no tocante à solução dos conflitos; uma breve visualização de seu funcionamento como órgão: suas etapas, os prazos a serem cumpridos pelas partes litigantes; e, finalmente, exporá quais os princípios gerais do Direito que norteiam o OSC nas suas decisões, demonstrando qual a importância e utilidade da interpretação destes princípios para a solução dos conflitos.

\section{MECANISMO DE SOLUÇÃO DE CONTROVÉRSIAS DA OMC}

\footnotetext{
1 Trabalho apresentado na disciplina de Direito Internacional Economico: Comercio Internacional, da Faculdade de Direito da Universidade Federal do Rio Grande do Sul, ministrada pelo Prof. Dr. Fabio Morosini.
}

Revista Brasileira de Direito Internacional, Curitiba, v.7, n.7, jan./jun.2008 
A Organização Mundial do Comércio foi o resultado mais significativo obtido na Rodada Uruguai, que se iniciou em 1986 na cidade de Punta Del Este, terminando após longos oito anos de negociações em Marraqueche, no Marrocos.

Denota-se na OMC tanto um sentido de continuidade do sistema anterior $\left(\mathrm{GATT}^{2}\right)$, no tocante a algumas diretrizes e princípios, como uma ruptura e transformação, decorrente justamente dos novos anseios que não encontravam suporte no sistema anterior ${ }^{3}$.

A OMC é considerada uma organização internacional, dotada de personalidade jurídica, sendo administrativamente autônoma e dispondo de quadro permanente de funcionários públicos, equiparados a funcionários públicos internacionais para efeitos de proteção, de deveres e de imunidades.

Apresenta a seguinte estrutura institucional:

a) Conferência Ministerial (Ministerial Conference) ${ }^{4}$ : é o órgão máximo da OMC, composto por representantes de todas as Partes Contratantes, que se reunirá pelo menos uma vez a cada dois anos, e tem como atribuições desempenhar todas as funções da OMC, adotando as disposições necessárias para tais fins, podendo também decidir sobre todos os assuntos compreendidos no âmbito de qualquer dos Acordos Comerciais Multilaterais. Ela ainda criou, seguindo instruções contidas nos termos do Acordo Constitutivo da OMC, três comitês que servem de auxílio para a concretização de suas funções;

b) Conselho Geral (General Council): composto por representantes de todos os Membros e que se reunirá quando necessário. Dentre algumas de suas funções, podemos citar: estabelecer acordos de cooperação com outras organizações intergovernamentais que tenham áreas de atuação relacionadas com as

\footnotetext{
${ }^{2}$ Interessante notar que as exceções ao livre-comércio, contempladas nos artigos XX e XXI do Acordo Constitutivo do GATT, para as quais não existe controle procedimental específico, sujeitam-se ao exame do Órgão de Solução de Controvérsias, ao qual cabe verificar se não houve, na hipótese, restrição arbitrária do comércio ou prática disfarçada de protecionismo.

${ }^{3}$ Neste sentido, assim leciona Alberto Amaral: "A continuidade é perceptível na adoção pela OMC dos princípios que nortearam a atuação do GATT e no acolhimento dos acordos de liberalização comercial negociados durante as antigas rodadas. A ruptura, por outro lado, ocorre quando a disciplina criada pelo GATT se revela insuficiente para responder de forma adequada às tensões provocadas pela globalização da economia. $\mathrm{O}$ aparato normativo e institucional existente não se ajustava à nova necessidade de regulação estimulada pela aceleração da interdependência e interpenetração dos mercados". AMARAL JÚNIOR, Alberto do (Org.). A Reforma do Sistema de Solução de Controvérsias da OMC e os Países em Desenvolvimento. São Paulo: S. Ed., 2006. P. 50 e 51.

${ }^{4}$ A Conferência Ministerial e o Conselho Geral gozam de poderes para autorizar a interpretação dos acordos multilaterais sempre que resoluções nesse sentido são adotas por pelo menos três quartos dos Membros da OMC.
}

Revista Brasileira de Direito Internacional, Curitiba, v.7, n.7, jan./jun.2008 
da OMC, bem como consultar e cooperar com Organizações NãoGovernamentais dedicadas a assuntos relacionados com os da OMC. Ele também pode ser estabelecido nas situações previstas no ESC, onde irá desempenhar as funções do Órgão de Solução de Controvérsias;

c) Órgão de Solução de Controvérsias (Dispute Settlement Body - DSB): estabelecido pelo Artigo $2, \S 1^{\circ}$, do ESC, ele possui como atribuições responder a consultas formuladas e a solucionar controvérsias surgidas entre os Membros a respeito das matérias constantes dos acordos abrangidos pelo Acordo Constitutivo e seus Anexos, estabelecer Grupos Especiais (panels), adotar Relatórios elaborados por estes e pelo Órgão Permanente de Apelação (Standing Appellate Body), supervisionar a aplicação das decisões e das recomendações contidas nos Relatórios adotados e autorizar a suspensão de concessões e de outras obrigações determinadas pelos acordos abrangidos;

d) Órgão Permanente de Apelação (Standing Appellate Body): estipulado pelo Artigo $17, \S 1^{\circ}$, do ESC, é o órgão responsável por receber as apelações formuladas contra os Relatórios dos Grupos Especiais. Ela também recebe as comunicações escritas de terceiros interessados na controvérsia quando esta já se encontra na fase de apelação;

e) Secretariado (Secretariat): é chefiado por um Direitor-Geral indicado pela Conferência Ministerial. Este diretor irá indicar os integrantes do pessoal da Secretaria, que são funcionários internacionais responsáveis por desempenhar as atividades constantes nos regulamentos adotados pela Conferência Ministerial. O DireitorGeral e o Secretariado não solicitam e nem recebem instruções de qualquer governo ou autoridade externa à $\mathrm{OMC}$.

Como fonte de lei material da OMC, podemos citar: o Acordo Constitutivo da OMC, os Anexos 1A, 1B, 1C e o Anexo 4. Este último engloba os acordos plurilaterais que apenas obrigam as partes que por eles se comprometeram.

Já como conteúdo de caráter de lei processual, encontramos o Anexo 2 (Entendimento Relativo às Normas e Procedimentos sobre Solução de Controvérsias - ESC ou DSU), que justamente dispõe sobre o mecanismo de solução de controvérsias, complementado pelos Working Procedures - normas elaboradas pela OMC para complementar o Art. 17 (Apelação) do referido Anexo 2.

Com relação aos tipos de decisões proferidas pelo OSC, elas podem ser agrupadas de acordo com o comando que emanam da seguinte forma:

a) Altere-se a legislação interna;

Revista Brasileira de Direito Internacional, Curitiba, v.7, n.7, jan./jun.2008 
b) Removam-se as barreiras vedadas;

c) Compensem-se prejuízos;

d) Conformem-se às obrigações assumidas perante a comunidade internacional quando da assinatura da Ata Final em Marraqueche.

O cumprimento das determinações e recomendações deve ser obrigatório e imediato (período variável e razoável de tempo) para que o Poder Legislativo e/ou Executivo do Membro infrator proceda à adequação da respectiva legislação interna aos Acordos da OMC.

As decisões do Mecanismo de Solução de Controvérsias baseiam-se na Convenção de Viena sobre o Direito dos Tratados (1969) e nos seguintes princípios: devido processo legal, boa-fé, lealdade processual, distribuição do ônus da prova, duplo grau de jurisdição, igualdade processual da partes, economia processual, adstrição ao pedido e efetividade ${ }^{5}$, que serão analisados adiante no trabalho.

\subsection{FINALIDADE E IMPORTÂNCIA}

O Entendimento Relativo às Normas e Procedimentos sobre Solução de Controvérsias (ESC) foi adotado pelo Decreto n. ${ }^{\circ} 1.355$, de 30/12/1994, publicado no Diário Oficial da União (DOU) em 31/12/1994, representando a incorporação no plano nacional brasileiro da "Ata Final que Incorpora os Resultados das Negociações Comerciais Multilaterais da Rodada Uruguai”. O documento acima citado, em seu Artigo 2 assim estabelece:

\footnotetext{
5 "Em compasso com as mudanças trazidas pela globalização, a OMC é um sistema de regras que ordena o mercado mundial ao definir os comportamentos lícitos e ilícitos, além de prever mecanismos que garantam o cumprimento das suas normas. Instrumento vital para a manutenção da ordem, as regras econômicas são o produto de compromissos entre Estados que não raro possuem interesses distintos. Não são emanações da consciência coletiva nem refletem de modo direto o poder e o interesse dos Estados e, ao contrário do que se sustentou, não são dados imanentes que surgem das necessidades da troca. A mera coincidência dos interesses, por si só, não é suficiente para originar uma norma; é preciso que os sujeitos que participam do processo de nomogênese jurídica envidem esforços para converter simples expectativas em regras vinculantes por meio de comportamentos que muitas vezes se traduzem em concessões mútuas.

A OMC forma um sistema de regras, com lógica própria e princípios específicos, que regula a interdependência e permite as operações econômicas no mundo globalizado. (...)".AMARAL JÚNIOR, Alberto do (Org.). A Reforma do Sistema de Solução de Controvérsias da OMC e os Países em Desenvolvimento. São Paulo: S. Ed., 2006. P.51.
}

Revista Brasileira de Direito Internacional, Curitiba, v.7, n.7, jan./jun.2008 
"Pelo presente Entendimento estabelece-se o Órgão Solução de Controvérsias para aplicar as presentes normas e procedimentos e as disposições em matéria de consultas e solução de controvérsias dos acordos abrangidos, salvo disposição em contrário de um desses acordos. Conseqüentemente, o OSC tem competência para estabelecer Grupos Especiais (Panels), acatar Relatórios dos Grupos Especiais e do Órgão de Apelação, supervisionar a aplicação das decisões e recomendações e autorizar a suspensão de concessões e de outras obrigações determinadas pelos acordos abrangidos. (...)".

Já no seu Artigo $3, \S 2^{\circ}$, encontramos a finalidade deste sistema de solução de controvérsias, que seria "o elemento essencial para trazer segurança e previsibilidade ao sistema multilateral de comércio. Os Membros reconhecem que esse sistema é útil para preservar direitos e obrigações dos Membros dentro dos parâmetros dos acordos abrangidos e para estabelecer as disposições vigentes dos referidos acordos em conformidade com as normas correntes de interpretação de direito internacional público".

De modo geral, este mecanismo tem como objetivo principal preservar os direitos e as vantagens obtidas pelos seus Membros no âmbito das práticas multilaterais de comércio, impedindo que eles hajam de forma unilateral, suspendendo benefícios antes acordados com os demais Membros. ${ }^{6}$

\subsection{PRINCIPAIS MUDANÇAS DO SISTEMA DE SOLUÇÃO DE CONTROVÉRSIAS DO GATT/1947 COM RELAÇÃO AO DA OMC}

O GATT caracterizou-se como um sistema baseado no trato diplomático entre as partes e não um sistema baseado em regras normativas pelas quais os Estados sentiam-se impelidos a obedecer.

Dentre as principais críticas formuladas ao sistema do GATT, podemos citar:

\footnotetext{
6 Vale lembrar aqui que os Estados Unidos são um dos países mais acusados de praticarem atos unilaterais de retaliação. Eles fundamentam suas atitudes na Seção 301 do Ato Comercial de 1974, que "autoriza o escritório do representante comercial dos EUA (USTR) a investigar e sancionar práticas comerciais consideradas "desleais" aos interesses norte-americanos. Essas sanções, tanto de caráter tarifário como não-tarifário, são estabelecidas de forma a impactar adversamente as importações dos países que de forma "injustificável" ou "não-razoável" restringirem as exportações dos EUA". Disponível em: http://www.cjf.jus.br/revista/numero4/artigo10.htm, acessado em 13/06/2009.
}

Revista Brasileira de Direito Internacional, Curitiba, v.7, n.7, jan./jun.2008 
1. a demora e incerteza intrínsecas ao procedimento, já que inexistia um direito à constituição do painel, pois as partes contratantes deliberavam sobre a sua criação de forma discricionária. Não havia limites temporais para as várias fases em que o procedimento se desdobrava, como as consultas, o pedido de instituição de um painel e o julgamento final da disputa;

2. a ausência de rigor e clareza das decisões;

3. a dúvida relativa à adoção do relatório elaborados pelo painel, devido à predominância da regra do consenso;

4. a lentidão em se adotarem as recomendações constantes dos relatórios e o descumprimento parcial ou total da decisão proferida. ${ }^{7}$

Ademais, a principal falha do sistema do GATT perdurou até quase a sua extinção: o chamado "consenso positivo", através do qual qualquer Parte Contratante, inclusive a que saiu perdendo a disputa, tinha o direito de vetar a adoção da decisão do painel pelo Conselho do GATT, impedindo, assim, que fosse conferida eficácia à implementação das decisões.

\subsection{INSTRUMENTOS JURÍDICOS QUE REGULAM O MECANISMO DE SOLUÇÃO DE CONTROVÉRSIAS}

A principal base do mecanismo de solução de controvérsias constituise no documento chamado de Entendimento Relativo às Normas $\mathrm{e}$ Procedimentos sobre Solução de Controvérsias, formulado no âmbito da Rodada Uruguai e em vigor desde $1^{\circ}$ de janeiro de 1995.

Concomitantemente ao Entendimento, encontram-se regras específicas de solução de controvérsias em diversos acordos da $\mathrm{OMC}$, que somente se aplicam aos conflitos iniciados após $1^{\circ}$ de janeiro de 1995 e que sejam relativos às matérias reguladas nos respectivos acordos. ${ }^{8}$

Tendo em vista que o mecanismo de solução de controvérsias da OMC encontra fundamento em vários diplomas, muito embora o Entendimento seja

\footnotetext{
7 TREBILCOCK, Michael J.; HOWSE, Robert. The regulation of international trade. London: Routledge, 2001. P. 55-56.

${ }^{8}$ Os acordos abrangidos que possuem disposições específicas sobre solução de controvérsias são: Acordo sobre aplicação de medidas sanitárias e fitossanitárias (artigo 11); Acordo sobre têxteis e vestuários - aplicável somente até 31/12/2004; Acordo sobre barreiras técnicas ao comércio (artigo 14 e Anexo 2); Acordo sobre a implementação do art. VII - valoração aduaneira; Acordo sobre subsídios e medidas compensatórias. Os demais acordos apenas fazem referência aos artigos XXII e XXIII do GATT de 1994, que são regulamentados pelo Entendimento.
}

Revista Brasileira de Direito Internacional, Curitiba, v.7, n.7, jan.jun.2008 
sua principal base jurídica, pode ocorrer diante de um caso concreto o que se denomina conflito de fontes.

Tratando-se de um conflito entre o Entendimento e os acordos abrangidos, por exemplo, o Acordo geral sobre serviços (GATS) ou o Acordo sobre os aspectos do direito da propriedade intelectual ligados ao comércio (TRIPS), o Artigo $1, \S 2^{\circ}$, primeira parte, assim estabelece:

\begin{abstract}
"As regras e procedimentos do presente Entendimento se aplicam sem prejuízo das regras e procedimentos especiais ou adicionais sobre solução de controvérsias contidos nos acordos abrangidos, conforme identificadas no Apêndice 2 do presente Entendimento. Havendo discrepância entre as regras e procedimentos do presente Entendimento e as regras e procedimentos especiais ou adicionais constantes do Apêndice 2, prevalecerão as regras e procedimentos especiais ou adicionais constantes do Apêndice 2. (...)"
\end{abstract}

Quanto aos conflitos que se verificarem entre diversos acordos, o mesmo diploma legal esclarece:

“(...) Nas controvérsias relativas a normas e procedimentos de mais de um acordo abrangido, caso haja conflito entre as regras e procedimentos especiais ou adicionais dos acordos em questão, e se as partes em controvérsia não chegarem a acordo sobre as normas e procedimentos dentro dos 20 dias seguintes ao estabelecimento do grupo especial, o Presidente do Órgão de Solução de Controvérsias previstos no parágrafo $1^{\circ}$ do art. 2 (denominado no presente Entendimento "OSC"), em consulta com as partes envolvidas na controvérsia, determinará, no prazo de 10 dias contados da solicitação de um dos Membros, as normas e os procedimentos a serem aplicados. O Presidente seguirá o princípio de que normas e procedimentos especiais ou adicionais devem ser aplicados quando possível, e de que normas e procedimentos definidos neste Entendimento devem ser aplicados na medida necessária para evitar conflito de normas".

Portanto, o ESC consubstancia-se como sendo o principal instrumento jurídico que contém as disposições a serem seguidas pelos seus Membros no tocante a solução de controvérsias existentes entre eles. 


\subsection{ESTRUTURA}

Trata-se de um conjunto de procedimentos que conjugam fases em que predomina a negociação diplomática clássica e outras, de caráter nitidamente jurídico-processual, incluindo aí uma fase designada como arbitragem, esta última expressão empregada em sentido peculiar e específico, dado que difere da arbitragem de Direito Internacional e também da de Direito Comercial Internacional.

O Mecanismo de Solução de Controvérsias é marcado nitidamente pelo caráter diplomático, no sentido de que sempre são estimulados a conversa e o acordo entre as partes. Percebe-se isso tanto no procedimento de consultas, após já ter sido proferido um Relatório, quando na ocasião em que os Membros da controvérsia têm que acordar o período considerado razoável para a implementação das medidas sugerida pelo OSC.

Denota-se que após a criação do Órgão de Apelação houve uma maior "jurisdicionalização" do OSC, pois os "julgadores" daquele possuem mandato por prazo determinado, além de ter sido adotado um rito quase-contencioso. Interessante notar, também, que não consta do Acordo Constitutivo a expressão "litígio" para designar a disputa entre as partes integrantes.

Outras características judiciais que se sobressaem do OSC podem ser apontadas como a possibilidade de adoção de mecanismos coercitivos com o intuito de obter o cumprimento das recomendações dos Relatórios dos Grupos Especiais ou do Órgão Permanente de Apelação, bem como de medidas compensatórias ou de retaliação.

Cumpre ressaltar a diferença existente entre o Mecanismo de Solução de Controvérsias e o Órgão de Solução de Controvérsias. Aquele consiste no Anexo II do Acordo Constitutivo da OMC, enquanto este último diz respeito ao órgão "jurisdicional" ao qual cabe a tarefa de gerir o primeiro através de sua Secretaria.

Passamos agora à análise das fases previstas no Entendimento sobre Solução de Controvérsias:

\section{a) Fase das consultas bilaterais:}

Revista Brasileira de Direito Internacional, Curitiba, v.7, n.7, jan./jun.2008 
Podemos encarar as "consultas", sob uma perspectiva do direito processual, como sendo uma das condições da ação, pois não haverá a instalação de um Grupo Especial sem que ela tenha ocorrido.

Após o estabelecimento da controvérsia, esta receberá uma denominação de acordo com a seguinte forma:

WT (World Trade)/ DS (Dispute Settlement) 33 (n. ${ }^{\circ}$ dado à controvérsia) United States (país reclamado ou respondent- Measure Affecting Imports of Woven Wool Shirts and Blouses, ou apenas a abreviação "Blouses".

\section{b) Fase dos Grupos Especiais:}

Esta fase está disciplinada pelas disposições contidas no Apêndice 3 do ESC, intitulado de "Procedimentos de Trabalho" (Working Procedure).

Ele dispõe que após 60 dias de negociações, contados da data do início da consulta, o país que suscitou a controvérsia poderá solicitar a constituição de um Grupo Especial para opinar sobre a causa.

Aplica-se, já nesta fase, a técnica do consenso negativo, situação em que não será instaurado o Grupo Especial caso haja o consenso de todos os Membros de sua desnecessidade.

O Artigo $8^{\circ}, \$ 6^{\circ}$, do ESC estabelece que o Secretariado do OSC proporá aos Membros o nome de três pessoas para integrar o Grupo Especial. Caso não haja a concordância das partes com relação aos indicados, dentro de 20 dias o Diretor-Geral da OMC poderá, mediante solicitação dos envolvidos, designar os integrantes do Grupo Especial.

O Grupo Especial disporá de 60 dias para elaborar o seu Relatório, que será encaminhado ao OSC para adoção. Esta não ocorrerá se houver consenso negativo ou se o Membro inconformado com a sugestão apelar para o Órgão de Apelação.

\section{c) Fase de apelação:}

É disciplinada pelo "Regulamento do Procedimento de Apelação" (Working Procedures for Appellate Review), datado de 28/02/1997, documento este identificado como WT/AB/WP/3.

A doutrina é unânime em dizer que a criação do Órgão Permanente de Apelação foi uma das inovações mais importantes no tocante à evolução do 
sistema de solução de controvérsias. Importante dizer que a apelação não é disponível em qualquer caso, não sendo possível o país "condenado" utilizá-la sempre que se sentir lesado pela decisão do Grupo Especial. Assim dispõe o Artigo 17, $\$ 6^{\circ}$, do ESC: "A apelação deverá limitar-se às questões de direito tratadas pelo Relatório do Grupo Especial e as interpretações jurídicas por ele formuladas" (grifo aposto).

O Órgão Permanente de Apelação deverá elaborar Relatório próprio (Appellate Body Report), não estando de forma alguma vinculado com o já proferido pelo Grupo Especial, podendo, desta forma, confirmar, modificar ou revogar as conclusões e decisões jurídicas deste (Artigo 17, §13).

O tempo máximo para esta etapa é de 60 dias. Após a sua conclusão e distribuição do Relatório entre os Membros, deverá ser adotado (cumprido) dentro de 30 dias, salvo se houver consenso negativo.

d) Fase de implementação das recomendações do Grupo Especial ou do Órgão Permanente de Apelação:

A próxima etapa consiste na manifestação do país faltante sobre as medidas que irá adotar para cumprir com a decisão do OSC. Caso ele não disponha de meios para imediatamente implementá-la, poderá ser-lhe concedido um prazo razoável para tanto.

\section{e) Fase da arbitragem:}

Poderá recorrer-se à arbitragem nos casos de o país vencido considerar insuficiente o prazo para cumprimento do Relatório, ou que algumas medidas indicadas por ele não são passíveis de serem concretizadas, ou, também, se as demais partes envolvidas discordem do seu argumento de que não é possível o cumprimento integral do Relatório ou, ainda, de que o tempo para cumprir com as recomendações será mais longo do que o acordado.

Quando estas hipóteses ocorrerem, poderão as partes, após consultas bilaterais, requererem que o prazo para cumprimento do Relatório seja estipulado pelo mecanismo conhecido por arbitragem. Este deverá ter início dentro dos 90 dias seguintes à adoção do Relatório pelo OSC (Artigo 21, §3 , do ESC). ${ }^{9}$

${ }^{9} \mathrm{O}$ procedimento da "arbitragem" foi adotado, por exemplo, nos seguintes casos: WT/DS27 Revista Brasileira de Direito Internacional, Curitiba, v.7, n.7, jan./jun.2008 


\section{f) Fase de retaliação ou de aplicação de medidas} ompensatórias:

O objetivo fundamental da fase de implementação, e da eventual suspensão de vantagens, é forçar o Membro a cumprir a decisão, tornando sua legislação interna compatível com as obrigações que assumiu no âmbito da OMC.

Para tanto, as partes insatisfeitas dispõem do Artigo $22, \S 1^{\circ}$, do ESC: "A compensação e a suspensão de concessões ou de outras obrigações são medidas temporárias disponíveis no caso de as recomendações e decisões não serem implementadas dentro de prazo razoável. No entanto, nem a compensação ou a suspensão de concessões ou de outras obrigações é preferível à total implementação de uma recomendação com o objetivo de adaptar uma medida a um acordo abrangido. A compensação é voluntária e, se concedida, deverá ser compatível com os acordos abrangidos".

O Membro faltante deverá adaptar a medida que the foi recomendada, quando não for possível fazê-la da maneira determinada, em outro acordo abrangido pela OMC do qual o reclamante faça parte. Ou, então, poderá acordar medidas compensatórias mutuamente satisfatórias às partes. Contudo, o $\S 2^{\circ}$ do mesmo dispositivo estabelece o prazo de 20 dias, depois de expirado o prazo razoável, para qualquer das partes, que hajam recorrido ao procedimento de solução de controvérsias, solicitar autorização do OSC para deixar de aplicar as suspensões decorrentes de acordos abrangidos ao Membro interessado.

Esta medida é considerada uma das últimas opções que os países podem adotar para verem o seu interesse atendido, pois ela irá criar, inevitavelmente, uma atmosfera de inimizade ainda maior entre os países. Claro que não se pode crucificar o país por proceder de tal forma, uma vez que se passou muito tempo desde as primeiras negociações, como no caso das consultas que antecedem a instauração do Grupo Especial, e, por isso, tendo em vista as diversas oportunidades que os Membros têm de entrarem em um

União Européia - Regime de Importação, Venda e Distribuição de Bananas e WT/DS48 União Européia - Medidas Relacionadas à Carne e seus Produtos (Hormônios).

Revista Brasileira de Direito Internacional, Curitiba, v.7, n.7, jan./jun.2008 
acordo, o país reclamante exaure suas forças na tentativa de obter solução favorável, não encontrando outra saída.

Diante deste pedido de retaliação, e da não implementação voluntária por parte do Membro reclamado, o OSC concederá a autorização para a suspensão de concessões. Se o reclamado discordar do montante das suspensões propostas pelo reclamante, a questão será submetida novamente à arbitragem para avaliação do valor devido da suspensão. O árbitro deverá ser preferencialmente um dos componentes do Grupo Especial que analisou o caso, incumbindo-lhe a missão de avaliar se a suspensão proposta equivale com o grau de anulação ou prejuízo causado ao Membro reclamante pela medida considerada ilegal.

\section{PRINCÍPIOS GERAIS DE DIREITO UTILIZADOS PELO ÓRGÃO DE SOLUÇÃO DE CONTROVÉRSIAS}

No campo do Direito Internacional, os princípios gerais do direito constituem uma de suas principais fontes, juntamente com os tratados e costumes internacionais. $\mathrm{O}$ artigo $38, \S 1^{\circ}$, do Estatuto da Corte Internacional de Justiça de Haia, dispõe que o Tribunal, cuja função é decidir conforme o Direito Internacional as controvérsias que lhe sejam submetidas, aplicará "os princípios gerais do Direito reconhecidos pelas nações civilizadas" ${ }^{10}$.

Como conceito de princípios gerais de direito, podemos considerar "as proposições de base ou 'proposições primeiras', escritas ou não escritas, que dominam os grandes sistemas jurídicos contemporâneos por sua importância, generalidade, e caráter abstrato, que the permite, por meio de um processo de transformação e de adaptação, fornecer os elementos de um regime jurídico suscetível de ser aplicado a situações concretas de caráter interno ou internacional"11.

${ }^{10}$ CRETELLA NETO, José. Direito processual na Organização Mundial do Comércio, OMC: casuística de interesse para o Brasil. Rio de Janeiro: Forense, 2003. P. 186.

${ }^{11}$ CRETELLA NETO, José. Direito processual na Organização Mundial do Comércio, OMC: casuística de interesse para o Brasil. Rio de Janeiro: Forense, 2003. P. 186.

Revista Brasileira de Direito Internacional, Curitiba, v.7, n.7, jan./jun.2008 


\title{
3.1 PRINCÍPIO DO DEVIDO PROCESSO LEGAL
}

Este princípio possui como origem histórica a tentativa de contenção do poder real ${ }^{12}$. A expressão due process of law passou a ser adotada pelas Declarações de Direitos proclamadas no século XVIII, com o objetivo de coibir o arbítrio dos governantes.

\begin{abstract}
"Deve ser referido o trabalho doutrinário dos juristas Coke (século XVII) e Blackstone (século XVIII), que culminou com a identificação do conceito de garantia de legalidade ínsito na cláusula due process of law com os procedimentos típicos do commom law britânico, acolhida por três importantes diplomas: o Petition of Rights, de 1628, o Habeas Corpus Act, de 1679, e o Act of Settlement, de 1701, que conferiram ao processo perante os tribunais ingleses garantias de cumprimento à lei, agora estendidas a todos os cidadãos".
\end{abstract}

No Brasil, este conceito passou a ser empregado apenas no Direito Processual, diferentemente da abrangência de aplicação deste princípio como é perceptível nos Estados Unidos. Este princípio foi incorporado explicitamente ao texto constitucional de 1988 no seu art. 5을 inciso LIV, que dispõe: "ninguém será privado da liberdade ou de seus bens sem o devido processo legal". Contudo, ele já era utilizado pela doutrina e jurisprudência antes mesmo de constar na Constituição.

Já no Direito Internacional, o conceito de due process of law incorporase a todos os mecanismos de solução de controvérsias ou litígios previstos em tratados, em especial nos multilaterais, porque assegura o necessário equilíbrio entre os Estados, necessariamente levando em consideração as diferenças entre as partes contratantes quanto ao poder econômico e a capacidade de cada qual, de mobilizar-se para defender seus interesses.

Quando um Membro considera que foi prejudicado durante o procedimento de solução de controvérsias, porque não the foi concedida

\footnotetext{
12 "O objetivo inicial era o de conferir direito de propriedade aos barões sobre as terras conquistadas, as quais, desde a época de Guilherme, o Conquistador (A.D. 1066), pertenciam à realeza, e eram distribuídas aos nobres, para que as utilizassem, sem que lhes fosse outorgado o correspondente título de propriedade." CRETELLA NETO, José. Direito processual na Organização Mundial do Comércio, OMC: casuística de interesse para o Brasil. Rio de Janeiro: Forense, 2003. P. 193.
}

Revista Brasileira de Direito Internacional, Curitiba, v.7, n.7, jan.jun.2008 
medida equivalente àquela permitida à outra parte em controvérsia, é freqüente que invoque inobservância do Órgão de Solução de Controvérsias ao due process of law.

Portanto, este princípio tem como escopo garantir um tratamento igualitário entre as parte envolvidas em alguma disputa e que façam uso do mecanismo de solução de controvérsias presente na OMC para solucionar o contencioso.

Como exemplos práticos de aplicação deste princípio pelo OSC, podem ser mencionados os seguintes casos:

- WT/DS 22 Brazil - Measures Affecting Desiccated Coconut: "A panel's terms of reference are important for two reasons. First, terms of reference fulfil an important due process objective - they give the parties and third parties sufficient information concerning the claims at issue in the dispute in order to allow them an opportunity to respond to the complainant's case. Second, they establish the jurisdiction of the panel by defining the precise claims at issue in the dispute."

- WT/DS 50 India - Patent Protection for Pharmaceutical and Agricultural Chemical Products:

"All parties engaged in dispute settlement...must be fully forthcoming from the very beginning both as to the claims involved in the dispute and as to the facts relating to the claims. Claims must be stated clearly. Facts must be disclosed freely. This must be so in consultations as well as in the more formal setting of panel proceedings. In fact, the demands of due process that are implicit in the DSU make this especially necessary during consultations. For the claims that are made and the facts that are estabilished during consultations do much to shape the substance and scope od subsequent panel proceedings...in the absence of the inclusion of a claim in the terms of reference, a panel must neither be expected nor permitted to modify rules in the DSU, ${ }^{\prime \prime}$.

Outra situação em que o due process foi assegurado durante 0 procedimento de solução de controvérsias pode ser encontrada em um Relatório do Órgão Permanente de Apelação, que permitiu a presença de advogados bem como a sua atuação nos procedimentos perante o OSC durante a fase de Apelação, direito este posteriormente reconhecido por um

\footnotetext{
${ }^{13}$ Ambos disponíveis em: http://www.wto.org/english/tratop_e/dispu_e/repertory_e/d2_e.htm, acessado em 13/06/2009.
}

Revista Brasileira de Direito Internacional, Curitiba, v.7, n.7, jan./jun.2008 
Grupo Especial, que permitiu que "private lawers" se manifestassem em audiências perante Grupos Especiais. ${ }^{14}$

\section{2 PRINCÍPIOS DA BOA-FÉ E DA LEALDADE PROCESSUAL}

O princípio da boa-fé é regra geral para a interpretação dos tratados internacionais, como preconizam as Convenções de Viena de 1969 e 1986. O tratado a ser interpretado é observado em sua totalidade, e não apenas em determinado dispositivo de que se busque obter o verdadeiro significado. Não é permitida a interpretação isolada de um ou mais artigos convencionais, mas o que deve buscar é a intelecção do tratado como uma única norma, incluindo-se aí seus anexos, preâmbulo, e demais considerações que porventura o integrem. Assim, a boa-fé deve ser entendida como a obrigação das partes contratantes (bem como do juiz ou árbitro, dependendo da situação) de interpretar o tratado de modo razoável, isto é, respeitando a norma jurídica e a vontade das partes.

No dizer de Celso D. de Albuquerque Mello, a boa-fé, presente em toda a ordem jurídica, e também como critério de interpretação, significa "lealdade, honestidade e sinceridade, opondo-se ao dolo e à fraude" ${ }^{15}$.

Da mesma forma, esclarece Hildebrando Accioly: "regra básica de interpretação: 'um tratado deve ser interpretado de boa-fé, segundo o sentido comum atribuível aos termos do tratado em seu contexto e à luz de seu objeto e finalidade""16.

Intimamente ligado com o princípio da boa-fé, encontramos o da lealdade processual, que tem por objetivo conter os ímpetos das partes litigantes e lhe propor uma conduta em juízo, que não impeça o processo de

\footnotetext{
${ }^{14}$ WT/DS27/AB/R, publicado em 02/07/1998.

${ }^{15}$ MELLO, Celso D. de Albuquerque. Direito Constitucional Internacional. Rio de Janeiro: Ed. Renovar, 1994. P. 26.

${ }^{16}$ ACCIOLY, Hildebrando. Manual de Direito Internacional Público. 15a ed., rev. e atual., São Paulo: Ed. Saraiva, 2002. P. 38.
}

Revista Brasileira de Direito Internacional, Curitiba, v.7, n.7, jan./jun.2008 
atingir seus objetivos, obstando tentativas de alterar o desfecho correto e justo mediante o emprego de artifícios ilícitos ${ }^{17}$.

A legislação brasileira acolheu amplamente estes princípios, como se denota no artigo 129, do Código de Processo Civil: "Convencendo-se, pelas circunstâncias da causa, de que autor e réu se serviram do processo para praticar ato simulado ou conseguir fim proibido por lei, o juiz proferirá sentença que obste aos objetivos das partes".

Já no plano internacional, a Convenção de Viena de 1969 sobre Direito dos Tratados (a qual entrou em vigor em 27/01/1980), no seu Artigo $31^{18}$ determina ao intérprete que siga a orientação de alguns elementos fundamentais, que são a boa-fé, a submissão ao sentido comum dos termos empregados e à leitura do tratado à luz de seu contexto, de seu objeto e de sua finalidade.

No mesmo sentido, os Artigos 18 e 26 da Convenção acima mencionada tratam do pacta sunt servanda ${ }^{19}$ e de práticas que venham a frustrar o objeto e a finalidade de um tratado ${ }^{20}$.

\footnotetext{
${ }^{17}$ MARQUES, José Frederico. Instituições de Direito Processual Civil. Vol II, 4ํㅗㄹ. Ed., Rio, Ed. Forense, 1971, vol.Il, p. 110.

18 "Artigo 31: 1. Um tratado deve ser interpretado de boa-fé, segundo o sentido comum dos termos do tratado em seu contexto e à luz de seu objeto e finalidade.

2. Para os fins de interpretação de um tratado, o contexto compreende, além do texto, seu preâmbulo e anexos:

a) qualquer acordo relativo ao tratado e feito entre todas as partes por ocasião da conclusão do tratado;

b) qualquer instrumento estabelecido por uma ou várias partes por ocasião da conclusão do tratado e aceito pelas outras partes como instrumento relativo ao tratado.

3. Será levado em consideração, juntamente com o contexto:

a) qualquer acordo posterior entre as partes relativo à interpretação do tratado ou à aplicação de suas disposições;

b) qualquer prática seguida posteriormente na aplicação do tratado pela qual se estabeleça o acordo das partes relativo à sua interpretação;

c) qualquer regra pertinente de direito internacional aplicável às relações entre as partes.

4. Um termo será entendido em sentido especial se estiver estabelecido que essa era a intenção das partes."

19 "Artigo 26: Todo tratado em vigor obriga as partes e deve ser cumprido por elas de boa-fé."

20 "Artigo 18: Um Estado deve abster-se da prática de atos que frustrem o objeto e a finalidade de um tratado:

a) se assinou ou trocou instrumentos constitutivos do tratado, sob reserva de ratificação, aceitação ou aprovação, enquanto não manifestar sua intenção de não ser tornar parte no tratado; ou

b) se expressou seu consentimento em obrigar-se por um tratado no período que precede a entrada em vigor, e com a condição de que esta não seja indevidamente retardada."
}

Revista Brasileira de Direito Internacional, Curitiba, v.7, n.7, jan./jun.2008 
Quanto ao plano processual, que tem lugar perante o OSC, o princípio da boa-fé é reafirmado em pelo menos três oportunidades:

* "Artigo 3, § 10, do ESC: Fica entendido que as solicitações de conciliação e a utilização dos procedimentos de solução de controvérsias não deverão ser intentados nem considerados como ações contenciosas e que, ao surgir uma controvérsia, todos os Membros participarão do processo com boa-fé e esforçando-se para resolvê-la. Fica ainda entendido que não deverá haver vinculação entre reclamações e contra-reclamações relativas a assuntos diferentes."

* "Artigo 4, § 3०: Quando a solicitação de consultas for formulada com base em um acordo abrangido, o Membro ao qual a solicitação for dirigida deverá respondê-la, salvo se mutuamente acordado de outro modo, dentro de um prazo de 10 dias contados a partir da data de recebimento da solicitação, e deverá de boa-fé proceder a consultas dentro de um prazo não superior a 30 dias contados a partir da data de recebimento da solicitação, com o objetivo de chegar a uma solução mutuamente satisfatória. (...)"

* Artigo 23, $\S \S 1^{\circ}$ e $2^{\circ}$ : este dispositivo visa ao fortalecimento do sistema multilateral, ressaltando que a conduta das partes deve se dar sob a perspectiva dos princípios da boa-fé e da lealdade processual.

Por sua vez, a lealdade processual vem acolhida nos seguintes dispositivos do ESC, entre outros:

* Artigo 12, § 4\%: "Ao determinar o calendário para seus trabalhos, o grupo especial deverá estipular prazos suficientes para que as partes em controvérsia preparem suas argumentações escritas" (no que lhes couber);

* Artigo 12, § 60. "Cada parte em controvérsia deverá consignar suas argumentações escritas ao Secretariado para transmissão imediata ao grupo especial e à outra parte ou às outras partes em controvérsia. A parte reclamante deverá apresentar sua primeira argumentação antes da primeira argumentação da parte demandada, salvo se o grupo especial decidir, ao estabelecer o calendário previsto no parágrafo $3^{\circ}$ e após consultar as partes em controvérsia, que as partes deverão apresentar suas argumentações simultaneamente. Quando se houver decidido pela consignação sucessiva das 
primeiras argumentações, o grupo especial deverá fixar um prazo rígido para recebimento das argumentações da parte demandada. Quaisquer argumentações escritas posteriores deverão ser apresentadas simultaneamente." (no que cabe às Partes);

* Artigo 12, § 11 : "Quando uma ou mais das partes for um país em desenvolvimento Membro, o relatório do grupo especial indicará explicitamente a maneira pela qual foram levadas em conta as disposições pertinentes ao tratamento diferenciado e mais favorável para países em desenvolvimento Membro que façam parte dos acordos abrangidos invocados pelo país em desenvolvimento Membro no curso dos trabalhos de solução de controvérsias" (quando se tratar de Parte considerada país em desenvolvimento).

A interpretação da boa-fé, no âmbito da OMC, implica na proteção e no atendimento às denominadas "legítimas expectativas" dos Membros ("legitimate expectations" ou "attentes legitimes"), conceito proveniente da jurisprudência européia, onde é conhecido como "princípio de confiança legítima", o qual faz parte do conjunto dos princípios fundamentais da Comunidade Européia, assegurados pelo Tribunal de Justiça das Comunidades Européias.

Aplicado ao caso concreto, encontramos a controvérsia WT/DS24 United States - Restictions on Imports of Cotton and Man-made Fiber Underwear, em que o Relatório afirmou:

\footnotetext{
"The relevant provisions of the Agreement on Textiles and Clothing have to be interpreted in good faith. Based upon the wording, the context and the overall purpose of the Agreement, exporting Members can ... legitimately expcet that market Access and investiments made would not be frustrated by importing Members taking improper recourse to such action".
}

Denota-se que o princípio da lealdade processual não deixa de ser um desdobramento do princípio da boa-fé, uma vez que se uma das partes age de má-fé, por exemplo, quando se abstém de fornecer informações relevantes, estará sim agindo de forma desleal para com a finalidade a que um processo com caráter mais judicial se propõe.

Revista Brasileira de Direito Internacional, Curitiba, v.7, n.7, jan./jun.2008 


\subsection{PRINCÍPIO DA DISTRIBUIÇÃO DO ÔNUS DA PROVA}

Muito se discute no Órgão de Solução de Controvérsias acerca do ônus da prova e a quem é este incumbido.

Primeiramente, é necessário diferenciar os vocábulos ônus e dever. Este consiste em algo que alguém tem de fazer (ou prestar, ou deixar de fazer) em relação a outrem, quando ligados entre si por relação jurídica própria. $O$ dever implica em obrigação que precisa, necessariamente, ser satisfeita. Já o ônus implica em faculdade, que pode ser satisfeita e caso isto não ocorra não implica em cumprimento forçado. Desta forma, a expressão "ônus da prova" significa: o encargo de provar, facultativamente. ${ }^{21}$

$\mathrm{O}$ atual Mecanismo de Solução de Controvérsias da OMC mantém a anterior prática do GATT 1947 quanto à distribuição do ônus da prova. Já em 1952, o Grupo Especial que havia decidido sobre a controvérsia Treatment by Germany of Imports of Sardines, em que a Noruega era reclamante, determinou que a alegação de que uma Parte violava qualquer dispositivo do GATT 1947 cabia à Parte reclamante, afirmando, verbis:

\footnotetext{
"The examination of the evidence submitted led the Panel to the conclusion that no sufficient evidence had been presented to show that the German Government had failed to carry out its obligations under Article I: 1 and Article XIII: $1{ }^{, 22}$.
}

No ESC não existe uma norma que trate explicitamente a este respeito, entretanto, a regra do Artigo $3, \S 8^{\circ}$, estabelece que em caso de não cumprimento de obrigações contraídas por força de qualquer dos acordos abrangidos, presumir-se-á que "que a medida constitua um caso de anulação ou de restrição. Isso significa que normalmente existe a presunção de que toda transgressão das normas produz efeitos desfavoráveis para outros Membros

\footnotetext{
21 "É da mais alta importância, em matéria probatória, determinar a quem cabe provar os fatos alegados em juízo, razão pela qual o sistema processual deve dispor de mecanismos apropriados, capazes de fazê-lo." CRETELLA NETO, José. Direito processual na Organização Mundial do Comércio, OMC: casuística de interesse para o Brasil. Rio de Janeiro: Forense, 2003. P. 209.

${ }^{22}$ CRETELLA NETO, José. Direito processual na Organização Mundial do Comércio, OMC: casuística de interesse para o Brasil. Rio de Janeiro: Forense, 2003. P. 210.
}

Revista Brasileira de Direito Internacional, Curitiba, v.7, n.7, jan.jun.2008 
que sejam partes do acordo abrangido, e em tais casos a prova em contrário caberá ao Membro contra o qual foi apresentada a reclamação". Ou seja, dentre as Partes em controvérsia cabe o ônus da prova ao que alega a violação, e ao reclamado, a prova de que a medida se justifica com fundamento em outra regra de exceção, permitida pelos acordos abrangidos.

Como em qualquer relação comercial, ambas as partes terão obrigações e deveres a cumprir. No Órgão de Solução de Controvérsias não seria diferente. A Parte que se sentiu lesada por alguma atitude realizada por um parceiro comercial, que também integre o quadro da OMC, poderá utilizarse do mecanismo de solução de controvérsias disponibilizado pela OMC, contudo, para que a sua reclamação seja sequer analisada, é preciso que ele demonstre de forma razoável qual a medida ilícita praticada pelo outro país e de que maneira esta atitude trouxe-Ihe danos. Uma vez feito isto, ele estará agindo de forma a defender os seus interesses, além de atribuir à parte acusada o ônus de provar que agiu de forma amparada na legislação da OMC, não tendo cometido uma violação a qualquer norma da organização.

Como exemplo veja-se o que estabeleceu o Órgão Permanente de Apelação, no Relatório adotado em 23.05.1997, referente à controvérsia WT/DS 33 United States - Measure Affecting Imports of Woven Wool Shirts and Blouses from India, de que:

“(...) various international tribunals, including the International Court of Justice have generally and consistently acceptes and applied that the party who asserts a fact, whether the claimant or the respondet, is responsible for providing proof thereof ... the burden of proof rests with the party, whether complaining or defending, that asserts the affirmative of a particular claim or defence (...)".

Podemos resumir a aplicação do princípio do ônus da prova pelo Órgão de Solução de Controvérsias nas seguintes regras gerais:

a) $\mathrm{O}$ Membro que alega violação à norma da $\mathrm{OMC}$, ou anulação ou prejuízo por parte de outro Membro deve prová-la, ou pelo menos oferecer elementos que sirvam de base para uma investigação de caráter técnico - isto é, de cunho científico, tributário, ou de outra natureza, sempre técnica e especializada - por parte do Órgão de Solução de Controvérsias, que permita comprovar o alegado;

Revista Brasileira de Direito Internacional, Curitiba, v.7, n.7, jan./jun.2008 
b) $\mathrm{O}$ Membro que nega ter praticado ato em violação às normas da OMC, ou que argumente, em sua defesa, não ter causado qualquer anulação ou prejuízo alegado pela outra parte, ou que admita ter praticado o ato apontado por outro Membro envolvido na controvérsia, mas que esse ato não constitui violação às normas da OMC nem tenha causado anulação ou prejuízo, deve refutar as alegações de violação, de anulação ou de prejuízo, seja demonstrando que o ato não foi praticado, ou, se o foi, que não configura a violação, anulação ou prejuízo de que é acusado, pois tem fundamento em norma contida em um ou mais acordos da OMC, que justifica a medida de exceção. ${ }^{23}$

\subsection{PRINCÍPIO DO DUPLO GRAU DE JURISDIÇÃO}

O princípio do duplo grau de jurisdição pode ser chamado também de princípio da recorribilidade, ou princípio da pluralidade de instâncias, ou ainda, princípio da pluralidade dos graus de jurisdição. Através dele toda decisão judicial está sujeita a reexame pelo Poder Judiciário, geralmente por órgão hierarquicamente superior ao que a prolatou, mediante provocação da parte que se sinta prejudicada pela decisão do juízo a quo.

Para atingir este objetivo é que o Acordo Constitutivo da OMC previu a criação e o funcionamento de um Órgão Permanente de Apelação - OPA (Standing Appelate Body), ao qual deverá ser dirigido o recurso, nos termos do Artigo 17:

“§ $1^{\circ}$ - O OSC constituirá um órgão Permanente de Apelação, que receberá as apelações das decisões dos grupos especiais. Será composto por sete pessoas, três das quais atuarão em cada caso. Os integrantes do órgão de Apelação atuarão em alternância. Tal alternância deverá ser determinada pelos procedimentos do órgão de Apelação".

O OPA não está adstrito ao Relatório formulado pelo Grupo Especial, podendo "confirmar, modificar ou revogar as conclusões e decisões jurídicas do grupo especial" (Artigo 17, § 13\%).

${ }^{23}$ CRETELLA NETO, José. Direito processual na Organização Mundial do Comércio, OMC: casuística de interesse para o Brasil. Rio de Janeiro: Forense, 2003. P. 216.

Revista Brasileira de Direito Internacional, Curitiba, v.7, n.7, jan./jun.2008 
Contudo, é interessante entender o que ocorre antes da fase recursal, pois o mecanismo de solução de controvérsias privilegia o diálogo entre as partes e destas com relação ao Grupo Especial, no dizer de Cretella Neto:

"O procedimento de revisão pelo órgão prolator consiste em que, antes da elaboração final do documento que irá se constituir no Relatório do Grupo Especial, seja obrigatoriamente realizada uma Etapa Intermediária de Exame (Interim Review, durante a qual, após consideração das réplicas e apresentações orais (das partes em controvérsia) o Grupo Especial deverá entregar às partes uma minuta de seu Relatório ("esboço", na versão brasileira de "draft Report") sendo-Ihes concedido prazo - fixado pelo próprio Grupo Especial - para que apresentem seus respectivos comentários por escrito (Artigo 15, $\S 1^{\circ}$, do ESC). Expirado o prazo, o Grupo Especial distribuirá às partes um Relatório provisório ("interim Report"), fixando novo prazo, desta vez para que as partes posam apresentar solicitação por escrito para que o Grupo Especial "reveja aspectos provisórios do Relatório antes da distribuição do Relatório definitivo aos Membros" (Artigo 15, § 2, do ESC)."24

Contudo, apesar de ser este um sistema tão compassivo e disposto a satisfazer ambas as partes, o uso que elas têm feito deste mecanismo verificase gravoso para a conclusão do litígio, pois elas utilizam-se da apelação ao OPA com o único objetivo de retardar o máximo possível o tempo de que disporiam para implementar o Relatório.

Assim, o que antes teria sido pensado como um modo de não causar injustiça à parte perdedora, impedindo que ela fosse obrigada a se submeter a uma decisão porventura arbitrária e possibilitando a ela a revisão da decisão proferida pelo Grupo Especial, passou a se caracterizar como um instrumento

\footnotetext{
24 "Como é típico do Mecanismo de Solução de Controvérsias, às partes em controvérsia é sempre oferecida a oportunidade processual para que se manifestem, e o Grupo Especial poderá inclusive, a pedido de uma ou de ambas as partes, "reunir-se novamente com elas para tratar de itens apontados nos comentários escritos" (Artigo $15, \S 2^{\circ}, 3^{a}$ parte, do ESC). Contrasta esse procedimento transparente e de boa técnica, que permite efetiva discussão das partes com os julgadores, com o previsto no sistema jurídico-processual brasileiro, por exemplo, em que via de regra, o juiz a quo simplesmente mantém sua decisão inicial, deixando de fundamentá-la adequadamente, conquanto esdrúxula, plena de omissões, contradições e/ou obscuridades, ao arrepio da lei processual, da lógica, da Justiça". CRETELLA NETO, José. Direito processual na Organização Mundial do Comércio, OMC: casuística de interesse para o Brasil. Rio de Janeiro: Forense, 2003. p. 221.
}

Revista Brasileira de Direito Internacional, Curitiba, v.7, n.7, jan./jun.2008 
para retardar o seu cumprimento, um meio de ganhar tempo e continuar se beneficiando de práticas protecionistas ou abusivas que esteja cometendo em face da outra parte. Esta seria a crítica atual feita à aplicação do princípio do duplo grau de jurisdição.

\section{CONCLUSÃO}

Foi possível perceber, através da elaboração deste trabalho, que a transição do sistema de solução de controvérsias do GATT/1947 para o que adveio com a criação da OMC era medida imprescindível a ser realizada, a fim de obter uma melhoria no grau de efetivação das medidas, uma vez que o novo mecanismo trouxe como característica um sistema mais judicializado, com prazos pré-estabelecidos de cumprimento das etapas, criando uma jurisdição compulsória para os seus Membros que ficaram obrigados a recorrer e acatar as normas e procedimentos subtraídos do ESC.

Ademais, constatou-se que os princípios gerais de direito possuem larga aplicação no âmbito de suas decisões, o que garante maior força e legitimidade a elas, eis que encontram larga aceitação pelos países que compõem a OMC.

Uma avaliação final do sistema de solução de controvérsias da OMC nos permite concluir que este sistema trouxe um maior grau de previsibilidade e estabilidade das relações econômicas internacionais.

\section{REFERÊNCIAS}

ACCIOLY, Elizabeth. Sistema de Solução de Controvérsias em Blocos Econômicos. Coimbra: Livraria Almedina, 2004.

AMARAL JÚNIOR, Alberto do (Org.). A Reforma do Sistema de Solução de Controvérsias da OMC e os Países em Desenvolvimento. São Paulo: S. Ed., 2006.

BARRAL, Welber Oliveira. O Comércio Internacional. Belo Horizonte: Del Rey, 2007. $168 \mathrm{p}$.

Revista Brasileira de Direito Internacional, Curitiba, v.7, n.7, jan./jun.2008 
CHARNOVITZ, Steve. Rethinking WTO Trade Sanctions. The American Journal of International Law, Vol. 95, No. 4 (Oct., 2001), pp. 792-832. American Society of International Law. Disponível em: http://www.jstor.org/stable/2674626.

Acessado em: 02/05/2009.

CRETELLA NETO, José. Direito processual na Organização Mundial do Comércio, OMC: casuística de interesse para o Brasil. Rio de Janeiro: Forense, 2003.

DREYZIN DE KLOR, Adriana; PIMENTEL, Luiz Otávio; KEGEL, Patrícia Luíza. Solução de Controvérsias: OMC, União Européia e Mercosul. Rio de Janeiro: Konrad-Adenauer-Stiftung, 2004. 240 p.

GOMES, Eduardo Biacchi. Blocos Econômicos e Solução de Controvérsias Uma análise Comparativa a partir da União Européia e Mercosul. 2ª Ed. Curitiba: Juruá, 2005. 288 p.

LASPRO, Oreste Nestor de Souza. Duplo grau de jurisdição no direito processual civil. São Paulo: Revista dos Tribunais, 1995. 192p. (Coleção Estudos de Direito de Processo Enrico Tullio Liebman, 33).

MARQUES, José Frederico. Instituições de Direito Processual Civil. Vol II, $4^{\underline{a}}$ Ed., Rio, Ed. Forense, 1971, vol.II.

MELLO, Celso D. de Albuquerque. Direito Constitucional Internacional. Rio de Janeiro: Ed. Renovar, 1994.

PAULO PEREIRA, Ana Cristina (Org.). Direito Internacional do Comércio: Mecanismo de Solução de Controvérsias e Casos Concretos na OMC. Rio de Janeiro: Lumen Juris, 2003. 394 p.

SHAFFER, Gregory; SANCHEZ, Michelle; ROSENBERG, Barbara. The Trials of Winning at the WTO: What Lies Behind Brazil's Success. University of Minnesota Law School. Disponível em: http://ssrn.com/abstract=1137905. Acessado em: 28/04/2009.

TREBILCOCK, Michael J.; HOWSE, Robert. The regulation of international trade. London: Routledge, 2001. 